\title{
Burnout among Iranian nurses: a national survey
}

\author{
Sara Mahmoudi', Maasoumeh Barkhordari-Sharifabad ${ }^{2}$, Amir-Hosein Pishgooie ${ }^{3}$, \\ Foroozan Atashzadeh-Shoorideh ${ }^{4^{*}}$ (D) and Zahra Lotfi ${ }^{5}$
}

\begin{abstract}
Background: Nurses, particularly critical care nurses, are exposed to high levels of stress and burnout. Burnout is associated with many deleterious consequences affecting health care outcomes. The present study is intended to determine the dimensions of burnout in nurses on surgical, medical and critical care units and its relationship with demographic characteristics.
\end{abstract}

Methods: In this descriptive research study, performed at critical and non- critical care units, 743 nurses were randomly selected by quota sampling from medical sciences universities in Iran. Data collection instruments included a "demographic questionnaire" and the "Persian version of the Copenhagen Burnout Inventory. Data were analyzed using SPSS20.

Results: The findings showed that regarding all dimensions, the lowest level of burnout belonged to surgical wards whereas the highest level pertained to critical care wards indicating a significant difference among various aspects of burnout in different wards, i.e., surgery, medical, and critical care. There was no significant difference in gender, academic degree, and marital status in any of the aspects of burnout in critical care units; yet, the difference was significant between surgical and medical wards $(P<0.05)$. There were a negative significant correlation between some dimensions of burnout with age and nursing experience in critical care and medical wards $(P<0.05)$. Whereas in surgical wards, there were a positive significant correlation between some aspects of burnout with nursing experience and age $(P<0.05)$.

Conclusion: This study found that the critical care nurses have significantly higher level of burnout compared to the medical-surgical nurses. These results should be considered when planning burnout prevention schedules for nurses.

Keywords: Critical care, Medical, Surgical, Burnout, Nurse

\section{Background}

Burnout is defined by Kristensen as the physical and mental exhaustion experienced by everyone [1]. Burnout may be identified by loss of energy, which commonly occurs when people feel physically and mentally "exhausted" [2], and has three aspects: personal, work-

\footnotetext{
* Correspondence: f_atashzadeh@sbmu.ac.ir

${ }^{4}$ Department of Psychiatric Nursing and Management, School of Nursing \& Midwifery, Shahid Beheshti University of Medical Sciences, Vali-Asr Avenue, Cross of Vali-Asr and Hashemi Rafsanjani Highway, Opposite to Rajaee Heart Hospital, Tehran, Iran

Full list of author information is available at the end of the article
}

related, and client-related [1]. On the other hand, burnout is a long and continued reaction to prolonged emotional and interpersonal job stressors and stressful events that can influence both personal and organizational aspects [3-6]. As shown in many studies, burnout is a progressively significant public health problem, which has an important effect on the nurses' health and well-being, and the quantity and quality of patients care [7]. Additionally, it is also correlated to a mass of psychosomatic problems and weakened quality of life [8], and may influence psychological and physical

(c) The Author(s). 2020 Open Access This article is licensed under a Creative Commons Attribution 4.0 International License, which permits use, sharing, adaptation, distribution and reproduction in any medium or format, as long as you give appropriate credit to the original author(s) and the source, provide a link to the Creative Commons licence, and indicate if changes were made. The images or other third party material in this article are included in the article's Creative Commons licence, unless indicated otherwise in a credit line to the material. If material is not included in the article's Creative Commons licence and your intended use is not permitted by statutory regulation or exceeds the permitted use, you will need to obtain permission directly from the copyright holder. To view a copy of this licence, visit http://creativecommons.org/licenses/by/4.0/ The Creative Commons Public Domain Dedication waiver (http://creativecommons.org/publicdomain/zero/1.0/) applies to the data made available in this article, unless otherwise stated in a credit line to the data. 
disorders $[9,10]$. Moreover, burnout can have negative effects on the nurses' practice, patient safety [11, 12], and patients' satisfaction; also, it can increase the likelihood of work-related injuries and subsequent absence from work [12]. It also affects job ssatisfaction, and nurse turnover [13]. In fact, nurses' burnout not only threatens their own condition and health, but also impacts on the quality of care given to patients [8]. Burnout appears to differ across the different nursing specialties [14] and differences in burnout across work settings is not unique [15]. Regarding nursing specialties, acute and/or critical care nurses look to be at a significantly higher risk of burnout [14] as a result of the extremely demanding situation in emergency medicine (EM), hemodialysis (HD) and in intensive care units (ICU) [7].

Nursing shortage, lack of support at work, caring for very unwell patients, and perceived conflicts with patients or other members of staff and high workload are some of the reasons for occurrence of burnout in nurses. Also, the high level of burnout is connected to lack of satisfaction with wages, opportunity for advancement, study leave and a practice setting with insufficient staffing as well as resources, and absence of nurses' contribution in hospital management $[16,17]$.

Conditions such as these in Iran have led to nurses facing an increased probability of physical and psychological stress, which may cause burnout [18]. The results of several studies on burnout revealed that burnout prevalence among Iranian nurses is high [19]. Different studies have been carried out on stress and burnout among nurses in the general profession, but few studies were conducted among acute and critical care nurses [20]. There are a number of studies on burnout in Iran most of which have focused on general specialist nurses, occupational therapists, and psychologists. The findings of the studies on burnout in hospital nurses were controversial. A comparison of medical, surgery, psychiatry, and burns wards showed that nurses of psychiatry wards had meaningfully higher levels of emotional exhaustion and depersonalization compared to nurses working in other wards; burns wards nurses had significantly higher levels of personal accomplishment [21]. The authors did not find any research about burnout in emergency and hemodialysis specialist nurses in the Iranian context.

Besides, what looks more important is to measure the concept effectively, and to do so, a reliable validated scale is required. The Copenhagen Burnout Inventory (CBI) sufficiently measures the potential analyses of etiology and the results of burnout and workplace interventions [22]. The CBI has been well practical in health and human service centers [23].

\section{Aim}

This study will investigate the dimensions of burnout in nurses working in surgical, medical and critical care units, and its relationship with demographic characteristics.

\section{Method}

\section{Research design, participants and setting}

In this descriptive-analytical study, the participants were selected by quota sampling. A multistage randomized sampling used for increasing generalizability. Medical science university hospitals in Iran were divided to five areas as north, south, east, west and center. The mean number of beds in each hospital is 210. After random selection of hospitals in every area (15 hospitals), based on Cochrane sample size determination formula with 95\% confidence level, $2 \%$ Confidence Interval and population of 1158 nurses, the sample size was calculated about 781. Thirty-eight questionnaire were not returned and finally 743 questionnaires were collected. The inclusion criterion was: having at least $6 \mathrm{~m}$ of work experience as a member of nursing staff in the current clinical wards.

\section{Variable and instruments}

In this study, a demographic and occupational questionnaire and Persian Copenhagen Burnout Inventory (P$\mathrm{CBI})$ were used to collect the data.

\section{1- Demographic and occupational questionnaire}

For the demographic data, the participants were asked to state their age, gender, educational level, years of nursing experience, marital status.

\section{2- Persian Copenhagen burnout inventory (P-CBI)}

The four-factor P-CBI contains 19 items and uses a 5item Likert-type scale. Items have responses of frequency ranging from; 100 (always or very high degree), 75 (often or high degree), 50 (sometimes or somewhat), 25 (seldom or low degree) and 0 (never or very low degree). It includes four subscales of personal burnout (7 items), nature of work-related burnout (3 items), work aversion-related burnout (3 items) and client-related burnout (6 items). Use of these four subscales is specific for the Persian version of CBI. Total score on the scale is the average of the scores on the items. Cronbach's $\alpha$ coefficient for its subscales after factor analysis ranged between 0.84 and 0.89 . The test-retest reliability coefficients by the Intra-Class Coefficient correlation for subscales of personal burnout, nature of work-related burnout, work aversion-related burnout, as well as client-related burnout were reported as $0.95,0.84,0.83$, and $0.90(P<0.001)$, respectively. Higher scores for each sub-scale signified more burnout. No cutting-point or reference values exist for this scale [24]. 


\section{Data collection}

Collecting data was completed from May to September 2017. The questionnaires were distributed to the nurses after the first author had explained the goals of the research. Nurses were asked to respond at a convenient time, when they were not busy. Each questionnaire contained explanatory details about the survey, and a reply envelope was supplied. The nurses were asked to place their responses into the reply envelopes. The questionnaires were collected after 2 days.

\section{Ethical considerations}

Ethical approval and agreement were obtained from the Research and Ethics Committees of University of Medical Sciences. Informed written consents was also acquired from all the participants who took part in the study. All ethical issues of respondents' anonymity and confidentiality were observed in this study.

\section{Statistical analysis}

Statistical analyses were performed with SPSS20. Mean, standard deviation (SD) and frequency were presented to describe the variables. Independent-sample t-test and ANOVA were used when comparing groups on normally distributed variables.

\section{Results}

Of 743 participants of the study, 282 (37.95\%) were employed in the surgical ward, $302(40.64 \%)$ in the medical ward, and 159 (21.39\%) in the critical care wards. The total number of critical care wards was smaller than other wards. The greatest mean age was $33.81 \pm 8.09$ years and the greatest mean work experience was $9.78 \pm$ 7.22 years that pertained to the surgical ward. There was no significant difference in age, work experience, marital status and academic degree among the wards. In critical care units there were more males than in medical and surgical ones (Table 1).

Also, the findings indicated that among all dimensions of burnout, the lowest mean belonged to the surgical ward whereas the highest mean pertained to the critical care ward. There was a significant difference in various dimensions of burnout among different wards (Table 2).

The results further suggested that regarding personal burnout in males, the highest mean belonged to the medical ward whereas it pertained to critical care wards in the three other dimensions. In females, the highest mean of personal burnout pertained to critical care wards in all aspects. T-test demonstrated no significant difference between males and females in ICU wards in all aspects of burnout though, albeit, the difference was significant in other wards (Table 3). The results of T-test also suggested no significant difference in all dimensions of burnout in critical care ward with respect to academic degree, though the difference was significant in other wards so that nurses with a BS degree showed greater burnout (Table 3).

Additionally, the findings indicated that the highest mean pertained to critical care wards with respect to marital status in all aspects of burnout. Of course, the results of ANOVA indicated that marital status exerted no significant effect on burnout in critical care wards, though the difference was significant in all aspects in surgical ward and married group had highest mean of burnout. Also, the difference was significant in clientrelated burnout in medical ward with respect to marital status as being divorced exerted a significant effect on burnout level (Table 3).

There were a negative correlation between dimensions of "personal burnout" and "Work aversion-related burnout" and "client-related burnout" with age and nursing experience in critical care wards. In surgical wards, there were a positive correlation between dimension of "personal burnout" and nursing experience and also a positive correlation between dimension of "nature workrelated burnout" with nursing experience and age. Results of correlation test showed that there are a negative correlation between dimension of "work aversion-related burnout" and age and nursing experience in medical wards (Table 3).

\section{Discussion}

This study determined the dimensions of burnout in nursing staffs of surgical, medical and critical care units and its relationship with demographic characteristics.

The results indicated that among all aspects of burnout, the lowest mean belonged to surgical ward whereas the highest mean pertained to critical care ward. There was a significant difference in all aspects of burnout among various wards. Numerous similar studies have been conducted on nurses working in different wards. Nonetheless, the use of different instruments and unusual study samples makes comparison of results difficult.

Scholars have presented different findings on the extent of burnout in different units in Iran. Similar to the findings of the present study, Salimi et al. found high level of burnout and compassion fatigue among 400 nurses working in the intensive care units of Iranian hospitals [25]. In the study of Saharian et al., on 180 nurses from 5 hospitals in Shiraz/Iran, Nurses in psychiatric wards had higher levels of emotional burnout and depersonalization, and burn ward nurses had higher rates of personal accomplishment [26]. Another study on 100 nurses working in different units in Rudsar/Iran indicated that ER nurses had higher job burnout than other nurses [27]. 
Table 1 Demographic and occupational characteristics of the participants

\begin{tabular}{|c|c|c|c|c|c|}
\hline Variable & & Ward & $\boldsymbol{N}(\%)$ & Mean (SD) & $P$ \\
\hline \multirow[t]{4}{*}{ Age } & & Surgical & & $33.81(8.09)$ & .11 \\
\hline & & Medical & & $32.68(6.62)$ & \\
\hline & & Critical care & & $33.75(6.50)$ & \\
\hline & & Total & & $33.34(7.20)$ & \\
\hline \multirow[t]{4}{*}{ Nursing experience } & & Surgical & & $9.78(7.22)$ & .55 \\
\hline & & Medical & & $9.19(6.29)$ & \\
\hline & & Critical care & & $9.53(5.95)$ & \\
\hline & & Total & & $9.49(6.58)$ & \\
\hline \multirow[t]{8}{*}{ Gender } & Male & Surgical & $27(9.57)$ & & $<0.001$ \\
\hline & & Medical & $30(9.93)$ & & \\
\hline & & Critical care & $44(27.67)$ & & \\
\hline & & Total & $101(13.59)$ & & \\
\hline & Female & Surgical & $255(90.43)$ & & \\
\hline & & Medical & $272(90.07)$ & & \\
\hline & & Critical care & $115(72.33)$ & & \\
\hline & & Total & $642(86.41)$ & & \\
\hline \multirow[t]{8}{*}{ Nurse's educational level } & Bachelor of Science & Surgical & $263(93.26)$ & & .59 \\
\hline & & Medical & $284(94.04)$ & & \\
\hline & & Critical care & $152(95.60)$ & & \\
\hline & & Total & 699 (94.08) & & \\
\hline & Master of Science & Surgical & $19(6.74)$ & & \\
\hline & & Medical & $18(5.96)$ & & \\
\hline & & Critical care & $7(4.40)$ & & \\
\hline & & Total & $44(5.92)$ & & \\
\hline \multirow[t]{20}{*}{ Marital status } & Single & Surgical & $108(38.30)$ & & .34 \\
\hline & & Medical & $109(36.0)$ & & \\
\hline & & Critical care & $57(35.85)$ & & \\
\hline & & Total & $274(36.88)$ & & \\
\hline & married & Surgical & $165(58.50)$ & & \\
\hline & & Medical & $190(62.91)$ & & \\
\hline & & Critical care & 99 (62.26) & & \\
\hline & & Total & $454(61.10)$ & & \\
\hline & Divorce & Surgical & $6(2.10)$ & & \\
\hline & & Medical & $3(0.99)$ & & \\
\hline & & Critical care & $2(1.26)$ & & \\
\hline & & Total & $11(1.49)$ & & \\
\hline & Widow & Surgical & $3(1.10)$ & & \\
\hline & & Medical & $0(0.00)$ & & \\
\hline & & Critical care & $0(0.00)$ & & \\
\hline & & Total & $3(0.40)$ & & \\
\hline & Living alone & Surgical & $0(0.00)$ & & \\
\hline & & Medical & $0(0.00)$ & & \\
\hline & & Critical care & $1(0.63)$ & & \\
\hline & & Total & $1(0.13)$ & & \\
\hline
\end{tabular}


Table 2 Dimensions of occupational burnout among different wards

\begin{tabular}{|c|c|c|c|c|c|c|}
\hline Dimensions of burnout & Unit & Mean (SD) & Max & Min & $\mathrm{F}$ & $P$ \\
\hline \multirow[t]{4}{*}{ Personal burnout } & Surgical & $46.31(19.39)$ & 78.58 & 14.29 & 86.99 & $<0.001$ \\
\hline & Medical & $60.40(18.69)$ & 100 & 28.57 & & \\
\hline & Critical care & $69.85(18.27)$ & 100 & 25 & & \\
\hline & Total & $57.08(20.94)$ & 100 & 14.29 & & \\
\hline \multirow[t]{4}{*}{ Nature work-related burnout } & Surgical & $51.32(22.04)$ & 83.33 & 0 & 71.04 & $<0.001$ \\
\hline & Medical & $57.91(19.79)$ & 100 & 8.33 & & \\
\hline & Critical care & $76.04(21.66)$ & 100 & 25 & & \\
\hline & Total & $59.29(22.97)$ & 100 & 0 & & \\
\hline \multirow[t]{4}{*}{ Work aversion-related burnout } & Surgical & $37.58(13.73)$ & 66.67 & 8.33 & 236.43 & $<0.001$ \\
\hline & Medical & $43.47(23.86)$ & 100 & 0 & & \\
\hline & Critical care & $76.10(13.65)$ & 100 & 33.33 & & \\
\hline & Total & $48.22(23.68)$ & 100 & 0 & & \\
\hline \multirow[t]{4}{*}{ Client-related burnout } & Surgical & $45.36(22.65)$ & 100 & 8.33 & 114.60 & $<0.001$ \\
\hline & Medical & $63.71(21.16)$ & 100 & 63.71 & & \\
\hline & Critical care & $75.44(17.90)$ & 100 & 25 & & \\
\hline & Total & $59.25(24.12)$ & 100 & 8.33 & & \\
\hline
\end{tabular}

Similar results have been reported in other countries. Study of systematic review on ER nurses indicated a high level of occupational burnout among them so that, on the average, $26 \%$ of ER nurses suffer from burnout. Scholars have reported the mean weight percentage of respondents above the cut-off point as $26 \%$ for emotional burnout, $35 \%$ for depersonalization, and $27 \%$ for lack of personal accomplishment [28]. In addition, the results of the study, in the Małopolska region, indicated individuals employed in ICU wards have higher emotional burnout, higher depersonalization, and lower personal accomplishment. However, multidimensional model of analysis showed a negative significant correlation between working in ICU ward and depersonalization in their study. Indeed, working in ICU ward served as a protective factor against burnout for nurses due to imagination of awards (being more professional) [29]. Ghazanfar et al. reported similar findings in cardiac care units in Pakistan [30]. Other studies also showed that HD nurses were exposed to high levels of stress and moderate burnout [31, 32]. Another study findings suggested moderate-to-high levels of occupational burnout in nurses at various wards of hospital; yet, contrary to our findings, there was no statistically significant difference among nurses working in ICU, ER, and surgical wards [33].

The disparity in results may be attributed to the different instruments used by the studies, study samples or population, and the organizational structure used. It can be related to the prevailing conditions in the organization and the environmental conditions. In other words, patients referred to ICU are usually physically in critical condition. In fact Iranian ICU nurses in addition to tolerating the pervasive psychosocial pressures prevailing in all parts of the hospital such as nursing shortages, job dissatisfaction, poor social position of nurses and etc., they face certain pressures, such as the urgency of time, exposure to the critical condition of patients $s$ with poor prognosis, which in turn leads to negative emotions.

Furthermore, according to the study which was conducted in this regard, technology use in the organizational structure may be a stressful element. Consequently, by the growing use of technology, stress level rises in the workplace and professions that deal with modern technologies in critical care unit where nurses are exposed to higher workload and stress which can result in high level of burnout [34]. As a final point, critical nurses have to conduct various demanding roles such as advocator, caregiver, teacher, counselor and technician while patients stay in a critical care unit. These complex roles undertaken by these nurses in addition to organizational aspects of the work situation have led to critical nurses experiencing high levels of burnout.

It should be noted that in many cities of Iran, hospitals are small and there is not enough beds. For this reason, patients with neurological, nephrological, cardiac, and other problems are admitted to the medical ward. Patients admitted to the surgical ward are also candidates for various surgical procedures.

The results indicated that in both genders, critical care nurses suffered from greater burnout with no significant difference among them. In surgical wards, women 


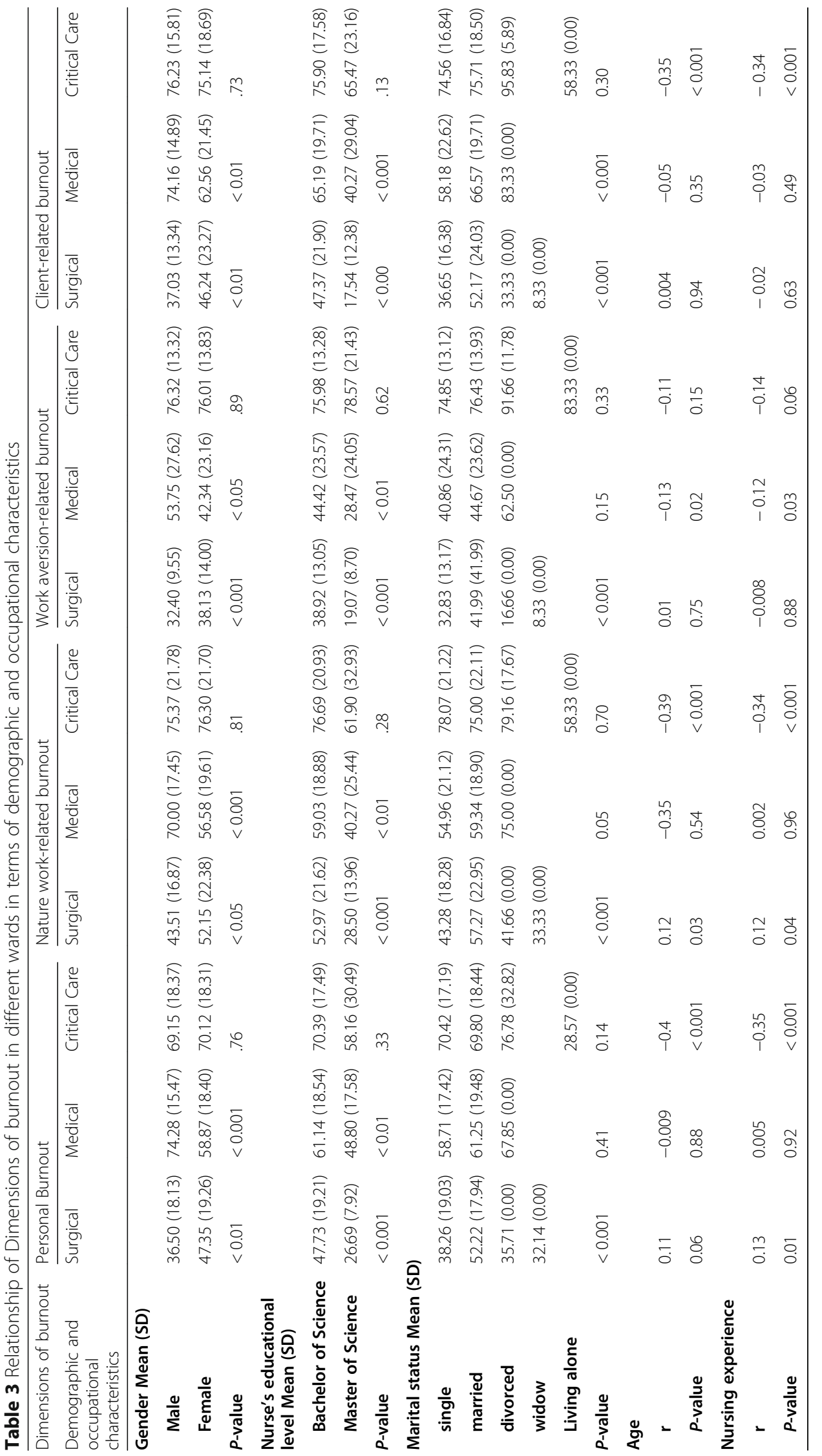


showed the greatest level of burnout in all aspects whereas in medical wards, men showed the highest levels of burnout indicating a significant difference between the two genders. The results of numerous studies demonstrated higher occupational burnout among males than females [31, 35]. Because of the patient's status in men's medical ward, nurses are exposed to more stress. There is a lot of evidence that patients hospitalized in the medical wards suffer from increased anxiety and depression due to the chronic nature of their illness. This can increase the vulnerability of nurses working in these wards [27, 36, 37]. On the other hand, work in the medical units is routine, uniform and unprofessional (the lack of specialized job duties), and this is unattractive for men and therefore causes more burnout. However, displacement and the multiplicity of work such as dressing, frequent check-ups of vital signs and severe shortage of manpower in surgical wards have led to greater burnout of women in surgical wards.

The results of the study further revealed that the highest level of burnout in all aspects in nurses holding a BS or MSc degree belonged to critical care wards; nevertheless, there was no significant difference in all aspects with respect to different academic degrees in critical care wards, yet, in surgical and medical wards, all aspects were significantly different in nurses holding a BS degree. The findings of the study by Demir suggested that higher academic degrees and higher occupational positions reduce occupational burnout [38]. The study by Rashedi et al. showed inadequate professional training leads to burnout in Iranian nurses [39]. Higher burnout in nurses with a BS degree can be due to insufficient education on how to manage work problems and increase resilience in the Iranian nursing education system. On the other hand, in the medical and surgical units, nurses by earning a higher degree, can benefit from higher job opportunities such as higher salaries, reduced work hours, and higher job qualifications in the future. For ICU nurses, because of the specialization of nursing care, it is possible to showcase their abilities and gain positive attitudes about themselves and patients; and while feeling confident, they will have a greater sense of power and mastery over their tasks.

Furthermore, the results indicated that marital status had no effect on burnout in critical care wards and the aspects were the same for all marital groups. Various studies have found no relationship between marital status and burnout in nurses and this lack of relationship was attributed to the lower probability of personal life in the occurrence of occupational burnout [37, 40, 41]. Unlike the results of the present study, one study demonstrated that particular variables, for example being single, are recognized as elements that may be related to high level of burnout in critical care nurses [34].
It should be pointed out that, in the present study, there was a significant difference in all aspects of burnout according to marital status in surgical wards and married group had highest mean of burnout. Family responsibilities, along with the variety of work and patients in the surgical ward, can be the cause of more burnout in all dimensions in surgical nurses.

Also, the difference was significant in client-related burnout in medical ward and being divorced exerted a significant effect on burnout level. Family-work conflict can be effective in developing burnout [42]. Studies have shown that family-work conflict and family composition are important determinants of burnout [43]. Anxiety and depression due to the chronic disease of patients hospitalized in the medical wards is associated with higher scores for client-related burnout [27, 36, 37]. Also, stressors arising from conflict with patients can lead to higher the client-related burnout [44].

Results showed there were a negative correlation between dimensions of "personal burnout" and "work aversion-related burnout" and "client-related burnout" with age and nursing experience in critical care wards. Studies are showed an increase in age is related to a decrease in reported burnout [45] People with low age and work experience become more stressed and feeling less self-sufficient due to lack of sufficient work experience and fear of error in critical situations [37].

In surgical wards, there were a positive correlation between dimension of "personal burnout" and nursing experience and also a positive correlation between dimension of "nature work-related burnout" with nursing experience and age. Study of Low et al. showed that older age of surgery residents was significantly associated with higher burnout [46].

Also, results showed that there are a negative correlation between dimension of "work aversion-related burnout" and age and nursing experience in medical wards. These association can be explained by the using of effective coping strategies by experienced nurses [39, 47, 48].

\section{Clinical implications of the results}

This study helps identification of high risk groups and risk factors for developing effective preventive strategies by identifying the dimensions of burnout and occupational and demographic characteristics in different units. These results should be considered when planning burnout prevention schedules for critical care nurses. Conducting some supportive interventions such as improved support from nurse managers and colleagues can act as a buffer against the stressors of workloads, the intense personal relationship, and repeated exposures to patient death. As responsible persons in charge of the emotional 
cost of the job, nurse managers have to actively ease psychological and spiritual support of nurses.

Formal programs such as mentoring, formal collegial support and increased nurse manager support promote psychological well-being and team cohesiveness [49]. Regular performance assessments including measuring of stress and burnout levels and a discussion on suitable coping strategies can also assist critical nurses to prevent the increase of burnout [50].

\section{Limitations of the study}

Some limitations ought to be considered in generalizing the findings of the present study. The cross-sectional design and the use of self-reporting may increase statistical bias. One limitation of the present study was the collecting questionnaires after 2 days, due to the uncontrollability of all conditions, some nurses may refuse to provide real answers and hence, misreport.

Another limitation was the impossibility of controlling the predictive variables, such as nursing shortage, the lack of a work support and increased patient severity, perceived conflicts with patients or other staff and high workload, as mentioned in previous studies, it is recommended to conduct studies in this area. Also, the stressful life events and work-family conflict that may influence the results of burnout were not considered in this study.

\section{Conclusion}

Among all dimensions of burnout, the lowest and highest mean belonged to the surgical and critical care unit, respectively. The critical care nurses have significantly higher levels of burnout compared to nurses in other wards.

In surgical wards, women showed the greatest level of burnout in all aspects whereas in medical wards, men showed the highest levels of burnout in all aspects indicating a significant difference between the two genders.

In surgical and medical wards, all aspects were significantly different in nurses holding a BS degree. There was a significant difference in all aspects of burnout according to marital status in surgical wards and married group had highest mean of burnout. Also, the difference was significant in "client-related burnout" in medical ward and being divorced exerted a significant effect on burnout level. Results showed there were a negative correlation between dimensions of "personal burnout" and "work aversionrelated burnout" and "client-related burnout" with age and nursing experience in critical care wards.

In surgical wards, there were a positive correlation between dimension of "personal burnout" and nursing experience and also a positive correlation between dimension of "nature work-related burnout" with nursing experience and age. There are a negative correlation between dimension of "work aversion-related burnout" and age and nursing experience in medical wards.

\section{Abbreviations}

EM: Emergency; HD: Hemodialysis; ICU: Intensive care unit; CBI: Copenhagen Burnout Inventory; P-CBI: Persian Copenhagen Burnout Inventory;

ANOVA: Analysis of variance; SD: Standard deviation; BS: Bachelor of Science; MSc: Master of Science

\section{Acknowledgments}

The authors also wish to thank all the participants. The authors wish to thank Victoria Skerrett who helped in native translation.

\section{Authors' contributions}

All authors (SM, MB-SH, A-HP, FA-SH, and ZL) have participated in the conception and design of the study. SM and ZL contributed the data collection and prepared the first draft of the manuscript. MB-SH and FA-SH critically revised and checked closely the proposal, the analysis and interpretation of the data and design the article. A-HP and MB-SH carried out the analysis, interpretation of the data and drafting the manuscript. MB-SH and FA-SH has been involved in revising the manuscript critically. All authors read and approved the final manuscript.

\section{Funding}

Shahid Beheshti University of Medical Sciences had no part in the design of the study and collection, analysis, and interpretation of data and in writing the manuscript.

\section{Availability of data and materials}

The datasets generated and analyzed during the current study are not publicly available due to an agreement with the participants on the confidentiality of the data but are available from the corresponding author on reasonable request.

\section{Ethics approval and consent to participate}

This study was approved by Ethics Committee of Shahid Beheshti University of Medical Sciences (IR.SBMU.REC.1397.053). To observe the ethical considerations, the research goals and procedures were elucidated to the participants, they were assured of information anonymity and confidentiality, and informed written consent was obtained from each nurse. They participated in the study voluntarily and could leave the study at any stage.

Consent for publication

Not applicable.

\section{Competing interests}

The authors declared no conflicts of interest with respect to the research, authorship, and/or publication of this article.

\section{Author details}

'Department of Nursing, School of Nursing, Dezful University of Medical Sciences, Dezful, Iran. ${ }^{2}$ Department of Nursing, School of Medical Science, Yazd Branch, Islamic Azad University, Yazd, Iran. ${ }^{3}$ Department of Critical Care Nursing, School of Nursing, AJA University of Medical Sciences, Tehran, Iran. ${ }^{4}$ Department of Psychiatric Nursing and Management, School of Nursing \& Midwifery, Shahid Beheshti University of Medical Sciences, Vali-Asr Avenue, Cross of Vali-Asr and Hashemi Rafsanjani Highway, Opposite to Rajaee Heart Hospital, Tehran, Iran. ${ }^{5}$ Department of Nursing, Royal Free Hospital, London, UK.

Received: 1 July 2019 Accepted: 12 July 2020

Published online: 16 July 2020

\section{References}

1. Kristensen TS, Borritz M, Villadsen E, Christensen KB. The Copenhagen burnout inventory: a new tool for the assessment of burnout. Work Stress. 2005;19:192-207.

2. Portoghese I, Galletta M, Coppola RC, Finco G, Campagna M. Burnout and workload among health care workers: the moderating role of job control. Saf Heal Work. 2014;5:152-7.

3. Molero Jurado MDM, Perez-Fuentes MDC, Gazquez Linares JJG, Simon Marquez MDM, Martos MA. Burnout risk and protection factors in certified nursing aides. Int J Env Res Public Heal. 2018;15:1116. 
4. Mbanga C, Makebe H, Tim D, Fonkou S, Toukam L, Njim T. Determinants of burnout syndrome among nurses in Cameroon. BMC Res Notes. 2018;11:893.

5. Ribeiro VF, Ferreira Filho C, Valenti VE, Ferreira M, de Abreu LC, de Carvalho TD, et al. Prevalence of burnout syndrome in clinical nurses at a hospital of excellence. Int Arch Med. 2014;7:22.

6. Tijdink JK, Vergouwen ACM, Smulders YM. Emotional exhaustion and burnout among medical professors; a nationwide survey. BMC Med Educ. 2014;14:183.

7. Ledikwe JH, Kleinman NJ, Mpho M, Mothibedi H, Mawandia S, Semo BW, et al. Associations between healthcare worker participation in workplace wellness activities and job satisfaction, occupational stress and burnout: a cross-sectional study in Botswana. BMJ Open. 2018;8:e018492.

8. Vasconcelos EM, De Martino MF. Preditores da síndrome de burnout em enfermeiros de unidade de terapia intensiva. Rev Gaúcha Enferm. 2017;38: e65354

9. Armenta-Hernández OD, Maldonado-Macías A, García-Alcaraz J, Avelar-Sosa L, Realyvasquez-Vargas A, Serrano-Rosa MA. Relationship between burnout and body mass index in senior and middle managers from the Mexican manufacturing industry. Int J Env Res Public Heal. 2018;15(541):1-21.

10. Seidler A, Thinschmidt M, Deckert S, Then F, Hegewald J, Nieuwenhuijsen K, et al. The role of psychosocial working conditions on burnout and its core component emotional exhaustion-a systematic review. J Occup Med Toxicol. 2014;9:10

11. Poghosyan L, Clarke SP, Finlayson M, Aiken LH. Nurse burnout and quality of care: cross-national investigation in six countries. Res Nurs Health. 2010; 33:288-98.

12. Tekindal B, Tekindal MA, Pinar G, Ozturk F, Alan S. Nurses' burnout and unmet nursing care needs of patients' relatives in a Turkish state hospital. Int J Nurs Pract. 2012;18:68-76.

13. Figueiredo-Ferraz H, Grau-Alberola E, Gil-Monte PR, García-Juesas JA. Burnout and job satisfaction among nursing professionals. Psicothema. 2012;24:271-6

14. Liu W, Zhao S, Shi L, Zhang Z, Liu X, Li L, et al. Workplace violence, job satisfaction, burnout, perceived organisational support and their effects on turnover intention among Chinese nurses in tertiary hospitals: a crosssectional study. BMJ Open. 2018;8:e019525.

15. Kashani M, Eliasson A, Chrosniak L, Vernalis M. Taking aim at nurse stress: a call to action. Mil Med. 2010;175:96-100.

16. Klopper HC, Coetzee SK, Pretorius R, Bester P. Practice environment, job satisfaction and burnout of critical care nurses in South Africa. J Nurs Manag. 2012;20:685-95.

17. Yuguero O, Marsal JR, Buti M, Esquerda M, Soler-González J. Descriptive study of association between quality of care and empathy and burnout in primary care. BMC Med Ethics. 2017;18:54

18. Dehghan Nayeri N, Nazari AA, Salsali M, Ahmadi F, Adib HM. Iranian staff nurses' views of their productivity and management factors improving and impeding it: a qualitative study. Nurs Health Sci. 2006;8:51-6.

19. Khodabakhsh MR, Mansuri P. Analysis and comparison between frequency and depth of job-burnout aspects among male and female nurses. Zahedan J Res Med Sci. 2011;13:40-2.

20. Moss M, Good VS, Gozal D, Kleinpell R, Sessler CN. An official critical care societies collaborative statement: burnout syndrome in critical care health care professionals: a call for action. Am J Crit Care. 2016;25:368-76.

21. Li H, Cheng B, Zhu XP. Quantification of burnout in emergency nurses: a systematic review and meta-analysis. Int Emerg Nurs. 2018;39:46-54.

22. Borritz M, Rugulies R, Bjorner JB, Villadsen E, Mikkelsen OA, Kristensen TS Burnout among employees in human service work: design and baseline findings of the PUMA study. Scand J Public Health. 2006:34:49-58.

23. Fong TCT, Ho RTH, Ng SM. Psychometric properties of the Copenhagen burnout inventory-Chinese version. J Psychol. 2014;148:255-66.

24. Mahmoudi S, Atashzadeh-Shoorideh F, Rassouli M, Moslemi A, Pishgooie $\mathrm{AH}$, Azimi H. Translation and psychometric properties of the Copenhagen burnout inventory in Iranian nurses. Iran J Nurs Midwifery Res. 2017;22:117-22

25. Salimi S, Pakpour V, Rahmani A, Wilson M, Feizollahzadeh H. Compassion Satisfaction, Burnout, and Secondary Traumatic Stress Among Critical Care Nurses in Iran. J Transcult Nurs. 2019:1-8.

26. Sahraian A, Fazelzadeh A, Mehdizadeh AR, Toobaee SH. Burnout in hospital nurses: a comparison of internal, surgery, psychiatry and burns wards. Int Nurs Rev. 2008;55:62-7.
27. Aghajani MJ. The professional burnout of nurses in different wards. J Res Dev Nurs Midwifery 2013:9:97-104 (in Persian).

28. Adriaenssens J, De Gucht V, Maes S. Determinants and prevalence of burnout in emergency nurses: a systematic review of 25 years of research. Int J Nurs Stud. 2015;52:649-61.

29. Nowacka A, Piskorz A, Wolfshaut-Wolak R, Piątek J, Gniadek A. Selected socio-demographic and occupational factors of burnout syndrome in nurses employed in medical facilities in Małopolska-preliminary results. Int J Environ Res Public Health. 2018;15:2083. https://doi.org/10.3390/ ijerph15102083.

30. Ghazanfar H, Chaudhry MT, Asar ZU, Zahid U. Compassion satisfaction, burnout, and compassion fatigue in cardiac physicians working in tertiary care cardiac hospitals in Pakistan. Cureus. 2018;10:e3416.

31. Karakoc A, Yilmaz M, Alcalar N, Esen B, Kayabasi H, Sit D. Burnout syndrome among hemodialysis and peritoneal dialysis nurses. Iran J Kidney Dis. 2016;10:395

32. O'Brien JL. Relationships among structural empowerment, psychological empowerment, and burnout in registered staff nurses working in outpatient dialysis centers. Nephrol Nurs J. 2011;38:475-81.

33. Fakhri MK, Aslipoor A. The burnout on nurses in ICU, emergency and surgery at teaching hospital Mazandaran University of Medical Sciences and relationship with perceived stress. Tolooebehdasht. 2015;14:138-150. (in Persian).

34. Böhmert M, Kuhnert S, Nienhaus A. Psychological stress and strainin dialysis staff: a systematic review. J Ren Care. 2011;37:178-89.

35. Hamaideh SH. Burnout, social support, and job satisfaction among Jordanian mental health nurses. Issues Ment Health Nurs. 2011;32:234-42.

36. Hooper C, Craig J, Janvrin DR, Wetsel MA, Reimels E. Compassion satisfaction, burnout, and compassion fatigue among emergency nurses compared with nurses in other selected inpatient specialties. J Emerg Nurs. 2010;36:420-7.

37. Shorofi SA, Karimzadeh M. Factors associated with burnout in nursing staff: a review article. Clin Excell 2015;3:56-70 (in Persian).

38. Demir A, Ulusoy M, Ulusoy MF. Investigation of factors influencing burnout levels in the professional and private lives of nurses. Int J Nurs Stud. 2003; 40:807-27. https://doi.org/10.1016/S0020-7489(03)00077-4.

39. Rashedi V, Rezaei M, Gharib M. Burnout and socio-demographic characteristics of nurses in Iran. Galen Med J. 2014:3:232-7.

40. Awa WL, Plaumann M, Walter U. Burnout prevention: a review of intervention programs. Patient Educ Couns. 2010;78:184-90.

41. Arab M, Rahimi A, Vali L, Ravangard R. Study of the relationship between nurses' work environment indices and their burnout aspects in TUMS teaching hospitals. Iran Occup Heal 2012;9:39-51 (in Persian).

42. Estryn-Behar M, Doppia MA, Guetarni K, Fry C, Machet G, Pelloux P, et al. Emergency physicians accumulate more stress factors than other physiciansresults from the French SESMAT study. Emerg Med J. 2011;28:397-410.

43. Ugwu FO, Ugwu C, Njemanze VC, Nwosu I. Family cohesion and family size moderating burnout and recovery connection. Occup Med (Chic III). 2019; 69:28-34.

44. Shimizutani M, Odagiri Y, Ohya Y, Shimomitsu T, Kristensen TS, Maruta T, et al. Relationship of nurse burnout with personality characteristics and coping behaviors. Ind Health. 2008:46:326-35.

45. McCormack HM, Maclntyre TE, O'Shea D, Herring MP, Campbell MJ. The prevalence and cause (s) of burnout among applied psychologists: a systematic review. Front Psychol. 2018;9:1897.

46. Low ZX, Yeo KA, Sharma VK, Leung GK, McIntyre RS, Guerrero A, et al. Prevalence of burnout in medical and surgical residents: a meta-analysis. Int J Environ Res Public Health. 2019;16:1-22

47. Soares JJF, Grossi G, Sundin Ö. Burnout among women: associations with demographic/socio-economic, work, life-style and health factors. Arch Womens Ment Health. 2007;10:61-71

48. Garrosa E, Moreno-Jimenez B, Liang Y, Gonzalez JL. The relationship between socio-demographic variables, job stressors, burnout, and hardy personality in nurses: an exploratory study. Int J Nurs Stud. 2008:45:418-27.

49. Duffield CM, Roche MA, Blay N, Stasa H. Nursing unit managers, staff retention and the work environment. J Clin Nurs. 2011;20:23-33.

50. George $V$, Haag-Heitman B. Nursing peer review: the manager's role. J Nurs Manag. 2011;19:254-9.

\section{Publisher's Note}

Springer Nature remains neutral with regard to jurisdictional claims in published maps and institutional affiliations. 